\title{
Deconstruction Study of Urban and Rural Integration Development Spatial Pattern in City-Country Fringe A Case Study of Xi'an
}

\author{
Xiaoming Qiao \\ Journal Editorial Department, Yunnan Normal University, Kunming \\ 650092, Yunnan China
}

\begin{abstract}
City-country fringe is the typical landscape area of continuously blurring, cross and integrating urban and rural areas under the background of rapid urbanization and the area deeply affected by city radiation and function expansion, and also the advance area of urban and rural integrated development. The study of citycountry fringe in foreign countries has been started as early as in 1930s. The research areas include the concept, content, features of city-country fringe, and discussed the issues of city-country fringe development rule, power mechanism and facility construction from multi-perspectives of regional economy, ecology, space and society, and have accumulated rich experience. In recent years, with the acceleration of the urbanization process, city-country fringe also becomes a focus and hotspot issue of the study of current urban space development. In face of the expanding trend of urban land use, the academic research of traditional city-country fringe and the practical study of planning building of related fields more focuses on the interests of city dominated perspective, which easily neglects the urban and rural dual structure of city-country fringe and unbalanced issue of rural-urban development, thus resulting in a serials of uncoordinated issues of city-country fringe. It is bound to require us to make in-depth research of urban and rural integration development issues at the level of city-country fringe, thus making the city-country fringe become the urban-rural integration, which will not only promote the effective play of urban growth momentum, but also boost the rapid development of the development of peri-urban areas. From the perspective
\end{abstract}


of urban and rural integration, the study starts from the urban and rural spatial structure integration of Xi'an urban-rural fringe area to make in-depth analysis and reveal the formation of Xi'an city-country fringe, development dynamic mechanism and the internal reason of spatial development missing. On this basis, the paper explores the appropriate model, methods and strategies of the urbanrural integration development of Xi'an city-country fringe.

Keywords: city-country fringe; Xi'an; urban-rural integration; dynamic mechanism; spatial mode structure;

\section{Introduction}

In 2013, the Central Committee Document No. 1 clearly stated, "We must comprehensively implement the spirit of the 18th Party Congress, unswervingly follow the road of socialism with Chinese characteristics, strive for the comprehensive construction of a well-off society, good agriculture and rural farmers as the most important task of the whole party, the "integration of urban and rural development" as a solution to the "three rural" issue of the fundamental way to coordinate and promote industrialization, information, urbanization, agricultural modernization, Focus on strengthening the foundation of modern agriculture support, and further promote the construction of new socialist countryside. "It can be seen that the current urban and rural integration has become a major national development strategy of the core and hot issues, different geographical characteristics of space for urban and rural integration research will be the core of future urban and rural issues. In recent years, with the acceleration of urbanization in China, the city in the diffusion mechanism from the inside and outside the role of the scope of its space continues to expand outspread. The countryside is also under the guidance of the internal mechanism of urbanization, showing a new spatial characteristic: "rural hollow", "rural urbanization", "village and village" and other rural areas landscape growth and change. In the two kinds of spatial interfaces, urban and rural elements are constantly "merging", "infiltrating", "transition", "assimilation" and "infection". Because of their special geographical unit characteristics, the region is not only urban economic and social development more active areas, but also people - to more sensitive areas of the relationship, but also more common areas of social problems.

\section{2 . Interpretation of relevant concepts}

\subsection{The connotation of urban-rural integration}

From the trajectory of the history of human settlements, it can be seen that cities and villages are not inherently binary spatial features, but a process of evolving and gradually forming. As the Marxist classic theory elaborates, the evolution of 
urban and rural areas undergoes the dialectical development process from "urbanrural interdependence" to "urban-rural confrontation" to "urban-rural integration", while urban-rural integration is achieved through the elimination of old division of labour. Production and education, change of work, to enjoy the benefits created by everyone, and urban and rural integration, so that all members of the ability to be comprehensive development. In addition, different disciplines on the understanding of urban and rural integration there are differences, such as North America and Europe, urban and rural planning history which highlights the connotation of urban and rural integration is a "urban-rural complex (Urban-rural Composition "is considered to be a result of the disorderly spread of large cities and the trend of suburbanization of population, thus forming a unique borderline between urban and rural areas.

Therefore, the definition of urban-rural integration can be understood as, under the conditions of the continuous development of productive forces, urban and rural space, facilities, economy, ecology, transportation and other elements of the overall consideration to break the urban-rural dual barriers, adjust the interests of urban and rural areas, Reconstruction of urban and rural development relations, reconstruction of urban and rural balance system, in order to achieve the free flow of urban and rural production factors and optimal allocation of urban and rural industries to optimize the coordination of urban and rural residents significantly improve the quality of life, urban and rural spatial integration of organic development goals, but also reflects the urban and rural policy system It is necessary to allocate public resources rationally and fairly in a balanced and balanced way, rather than artificially distinguishing the city from the countryside. In the process of urban-rural integration, both urban and rural areas can play their own advantages, so as to achieve the purpose of regional sustainable development. In summary, urban-rural integration is to achieve the liberalization of urban and rural factors flow, urban and rural institutional design fairness, urban and rural resource allocation efficiency, urban and rural industrial layout integration, urban and rural environmental protection, urban and rural spatial structure integration the equalization of urban and rural public facilities, the integration of urban and rural market elements, etc. The integration development of each branch will be an important component and connotation of urban-rural integration. At the same time, we should pay attention to the following points when we have a deep understanding of the connotation of the development of urban and rural integration.

\subsection{The connotation of urban-rural fringe}

As early as 1936, geographer He Louis found that the evolution of urban space structure in Berlin, Germany, which presents a typical regional landscape structure, urban built-up areas continue to spread out, gradually extended to the original rural areas, he put this typical "regional integrated landscape" called "urban-rural intersection." From the definition of the urban fringe in the early period, to the analysis of the inner structural features and the law of the urbanization development, from the point of view of the economic and social 
significance of the urban orientation, the study of the urban-rural fringe has been nearly 80 years. , And function, and then to the consideration of urban and rural integration under the background of countryside background, the urban-rural crisscross area is becoming the "key area", "social focus" and urban planning which must be confronted. "Forward position", and continue to be people's attention. From the initial conceptual meaning explanation, geographical features, spatial conditions, and so on, the content of the research also comes to the urbanrural integrated planning, integrated facility construction, dynamic mechanism and spatial suitable development pattern.

\section{The dynamic mechanism analysis of the urban - rural integration in the urban - rural fringe}

\subsection{The driving mechanism of urban - rural integration in urban - rural fringe}

The driving mechanism of urban-rural integration in the urban-rural crisscross area mainly includes inner self-motive force and external leading power. The endogenous motive force is mainly the geographical environment factor, location factor, resource structure, Advantages, employment advantages, information access advantages and other characteristics, due to close to the city core area, so the internal self-organization effect is obvious, it is easy to close the elements between urban and rural exchange, thus forming a platform for urban and rural exchange effects, Urban and rural space to become a new point of growth and become the forefront of urban and rural evolution. External guidance mechanism mainly refers to the external and economic factors, such as economic information, industry information, population information, housing system, land ownership, enterprise information, policy information, urban (rural) strategy, The influence of urban-rural integration tendency is often the "top-down" development mode under the government's control, which can induce the communication and fusion between urban and rural areas, thus reflecting an external guiding mechanism .

\subsection{The dynamic mechanisms details of urban-rural integration development in urban - rural fringe}

The spatial development of any urban area is inseparable from the geographical characteristics of the local environment. Since the date of settlement, the existence and development of settlements are subject to geographical differences in geographical environment. Therefore, the geographical environment is the basis for the development of urban and rural integration condition. Direction, speed and spatial pattern, and even in some places, the urban geographical environment is directly become the "threshold" of urban-rural spatial integration, such as the urban area of the plain because of the terrain. Therefore, relative to the urban-rural intertwining area of urban and rural diffusion mechanism, the geographical environment is "constraint and integration" parallel complex. 
The difference between urban and rural dual market structure is bound to achieve the free flow and mutual guidance of market elements within the urbanrural fringe. Urban and rural areas under the conditions of urban-rural integration should be set "ecology, life, production," the three elements of an integrated economic region should be business, entertainment, recreation, trade, traffic load space. In the context of urban-rural integration, urban-rural intersection of market-dependent will become stronger, each kind of market elements in the hope that the most efficient way to seek their own hinterland and places. Therefore, the close relationship between the urban and rural interfaces naturally determines the market orientation will be the core driving force for future urban and rural integration development.

In the integration of urban and rural construction, policy guidance is the flag and wind direction benchmark. Although urban and rural market elements can form free market forces in the urban-rural fringe area, they are not necessarily able to form urban-rural integration, but are more likely to induce long-term polarization effects under the economic growth and divert rural development, in the cycle of cumulative decline in the process, increase the imbalance between urban and rural areas. Therefore, in order to achieve the goal of urban-rural integration, we must also seek to coordinate the imbalance between urban and rural areas through the external security of policies, systems and plans. Such as optimizing the allocation of urban and rural economy, industry, social service facilities, land resources, etc., to play the role of government's planning and coordination, effectively guide the direction of industrial development and the direction of resource flow, so as to formulate appropriate Policies and institutions to guide the development of rural areas.

\section{4 .Deconstruction of urban-rural integration in the urban-rural fringe of Xi'an}

\subsection{Historical pattern analysis}

Most of the forms of urban space in ancient and modern times in Xi'an follow the separation of urban and rural space situation, with walls as the boundary is divided into inner and suburbs, therefore, early Xi'an urban and rural areas are also confined in the wall near the city. In 1950, Xi'an People's Government began to organize the preparation of "urban development plan in Xi'an." The whole city is surrounded by green belts. In the periphery of the city, the east and west are arranged in the higher education area, the north and south are arranged in the warehousing area, and the north and the east are two small airfields. In 1956, due to the influence of the "Great Leap Forward" and "Cultural Revolution", the growth of urban and rural in Xi'an was slow and not typical; in the 20th century, in $1960 \mathrm{~s}$, the urban-rural fringe area of Xi'an had reached $337 \mathrm{~km}^{2 ;}$ In the $1980 \mathrm{~s}$, since the Third Plenary Session of China's urban construction has entered a period of rapid development of the historical turning point, Xi'an urban-rural areas continue to expand outward, to the 90 's area has reached $587.0 \mathrm{~km}^{2}$; From 
1980 to 2000 the city master plan ", Xi'an airport moved out of the urban area and in the north, southwest, northeast direction increased five external highway entrances and exits, city layout and function from inland closed to open to outside change, urban and rural.

\subsection{Deconstruction of the real interest}

Most of the urban-rural fringe areas are related to urban directivity, which is mainly based on the subjective characteristics of the city centre. The emphasis is on the urban industrial structure, the construction of urban transport facilities, the extension of urban major projects It is easy to ignore the integration of urban and rural natural ecological environment structure of integration, leading to urban and rural ecosystem fragmentation; it is easy to ignore the complementary nature of urban and rural industrial structure and agricultural industrial base to optimize the coordination of urban industrial structure, Will be limited to urban construction within the city, leading to lack of coordination of urban and rural planning space. The most typical urban-rural fringe is mostly considered in the overall urban planning and village planning. Due to the difference of the two types of planning and technical systems, it is difficult to achieve effective integration. Therefore, the future development of urban and rural areas should be under the "Urban and Rural Planning Law" under the guidance of urban and rural integration into a coordinated whole to consider, and constantly coordinate urban and rural spatial layout, ecological layout, industrial layout, facilities layout, policy design, To avoid passive rural urbanization model, subject to the constraints of the city, but should be the interaction of urban and rural situation to achieve the integration of various elements of the integration of construction goals.

\subsection{The objective question is combed}

With the rapid development of Xi'an urbanization in recent years, some urban and rural landscape features which are in the urban-rural fringe area of Xi'an City, show typical construction disorder and space fragmentation. On the one hand, due to the lack of effective management of land use in the urban-rural fringe, construction land and rural homestead and idle construction land are intertwined in parallel. Various types of industrial land, commercial land, residential land and non- urban and rural land use are intertwined, Residential land - industrial land typical agricultural land (urban leisure agriculture, greenhouses vegetable land, horticultural land, flower land, etc.) in the core area of the city, the use of activities in the frequent changes in the core area of the city out of "commercial service facilities land - The land-use "map-bottom" landscape features are characterized by disorder and fragmentation; on the other hand, due to the diversity of the types of buildings used in the urban-rural fringe, it leads to neat planning Of the commercial housing and contiguous rural housing, University City, high-tech zones, independent business units, as well as the chaotic coexistence of urban villages, architectural styles vary greatly, the lack of integration of urban and rural architectural design. In addition, the unbalance of traffic, such as the messiness of living and traffic roads in the urban-rural fringe, 
and the difference between the accessibility of the roads and the functional elements such as tourist attractions, industrial parks, university new towns, living spaces and public service facilities.

\section{Conclusion}

Urban intercourse space is a comprehensive regional carrier of urban and rural economy, culture and society. The expansion of urban space is an economic, social and cultural phenomenon. The essence of spatial expansion is the result of the interaction between the city and surrounding rural hinterland. With the acceleration of China's urbanization process, the future of large and medium cities around China will continue to produce a wider range of urban-rural areas, the tasks of urban and rural planning and construction will be more severe. Urban-rural integration planning is the main goal of the future urban and rural development, urban and rural areas as a transitional zone between urban and rural areas, it should assume the task of urban and rural integration, coupled with the typical location advantages of urban and rural areas. The study of urban-rural integration of urban and rural areas will has very typical characteristics of the problem. Solving this typical area of urban and rural integration is not only the goal of future urban spatial growth, but also the key to promote the urbanization rapid development in rural areas.

\section{References}

[1] Jian Boxiu. Desakota and the Development of New Metropolitan Areas in China. Journal of Architecture and Urban Research, National Taiwan University, 55(12), pp.68-70, 2011

[2] Zhang Pei, Zhang Zhonghua. The International Progress of Urban-Rural Integration Research and the Typical National Development Experience. International Urban Planning, 8 (5), pp.87- 91, 2013

[3] Yu Wei, Song Jin-Ping, et al. Study on the Definition and Scope of Urban Fringe. Geographical Research and Development, 12(10), pp. 18- 20, 2012

[4] Gu Zhaolin, Chen Tian. Study on the Characteristics of the Marginal Areas in Chinese Metropolitan Areas. Journal of Geographical Science, 9(6), pp.58- 61, 2011

[5] Ban MaoSheng, Fang Chuanglin. Research Progress and Future Research Orientation of Domestic Urban Fringe. Journal of Urban Planning, 8(4), pp.85-87, 2014 